\title{
Analysis of Solution to Environmental Law Education for College Students
}

\author{
Yang Yang \\ School of Politic Science and Public Management, Southwest University, Chongqing, China \\ Email: yangyangtangxin@vip.qq.com
}

Received April 13 $3^{\text {th }}$, 2013; revised May $16^{\text {th }}$, 2013; accepted June $9^{\text {th }}, 2013$

\begin{abstract}
Copyright (C) 2013 Yang Yang. This is an open access article distributed under the Creative Commons Attribution License, which permits unrestricted use, distribution, and reproduction in any medium, provided the original work is properly cited.
\end{abstract}

\begin{abstract}
The environmental crisis is one of three major crises to human's development. But there are a series of issues in present for environmental law education of college students, such as this course, which are low offered and lack of sustainability, colleges and universities do not pay enough attention to it. They are weak in the relevant basic theory and they are lack of vocational training and so on. In order to solve the above problems, we can try to do the "two combinations". The first is the combination vocational training and basic knowledge and the second is combining vocational training in the classroom with outside of the classroom in environmental law.
\end{abstract}

Keywords: Environmental Law Education; Vocational Training of Environmental Law; Basic Knowledge of Environment

\section{Introduction}

Population crisis, the crisis of resources and environmental crisis are three major crises faced by human to develop. If these three crises can't be properly solved, humanity will be destroyed by themselves which is currently urgent problems faced by people in the world. The "sustainable development" as a proposition was put forward on Environment and Development by the United Nations Conference. The report to the Seventeenth National Congress of the Communist Party of China stressed that "We must pursue comprehensive, balanced and sustainable development. ... so that our people can live and work under the pleasant ecological environment conditions to achieve economic and social sustainable development". When it came to thoroughly apply the Scientific Outlook on Development, the concept of sustainable development was resonated among delegates who participated in this national congress. It is the concern of the rest of humanity to protect the environment. All the governments in the world should offer the relevant courses according to their curriculum conditions to help college students to form scientific opinion and ethic of environment.

\section{The Reason for Environmental Law Education}

To achieve this goal, China is facing a severe situation. As compared to they grew up in environmental education for the developed countries of Europe and the United States, we have not pay attention to it until 1996 when the Outline of National Environmental Publicity and Education(from1996 to 2010 year) has been promulgated by the State Environmental Protection Administration, the State Board of Education and the Central Propaganda Department.And then, the Coordination Committee of Provincial Environmental Propaganda and Education have been established in all provinces. The Ministry of Education decided to incorporate formally environmental education into the curriculum of the primary and secondary schools in China's eighth basic education curriculum reform that was carrying out not long ago, and the Guidelines of Environmental Education for the Primary and Second school was formulated. Our college students almost had never received any education about environment before entering the university. But as the main force in the social construction and the future builders, they will enter into different jobs and departments once graduated, and most of them will become decision makers, managers or practitioners at different levels. If they do not develop a good awareness of environmental laws or even their behave against environmental laws and regulations, the future of the nation will be worrying. So it is a great significance for China's environmental protection and sustainable development to strengthen their awareness. It has very strong plasticity for them in their college days that their outlook in life and world was formed maturely and normally. Generally speaking, there is an extremely important significance to strengthen their environmental law education. Through carrying out environmental law education in college and university, it can help them to definite environmental concept, form awareness of environmental rights and achieve the following six goals of environmental education finally: 1) awakening; 2) knowledge; 3) attitude; 4) skills; 5) evaluation capacity; 6) participation and so on. These will be more directed and targeted, more energy to get instant results. It is an important part of environmental education. It is aimed at forming the conception of environment by raising the public awareness of environmental law to protect their environmental rights and interests by means of law. Compared to environmental ethics education and environmental awareness education, it has a direct effect on the behavior of citizens, therefore it can produce a more direct social effect. 


\section{Problems and Solutions}

\section{Problems}

First of all, to reinforce the basis theoretical knowledge of environment. The current problems is that its mode is single and colleges and universities do not pay enough attention to it. In terms of colleges and universities which have offered the basic environmental education, it is usually associated with environmental protection technology, ecological ethics education in all aspects into a textbook, thus it is fewer hours for studying the content of environmental law. And it has a strong influence on environmental education for the traditional examination-oriented education ways to let the students lost the interest in learning related contents. It is the only reason to study it for students that is to cope with the examination. Such education mode makes students learn the knowledge only staying in theory, and not improving in practice. Even, many college teachers think that it's enough for college students to get a general idea about environmental knowledge. But scholars have found in the survey that few students can accurately explain the basic concepts of environment such as ecosystem, hydrosphere, light pollution and so on (Xu \& Zhu, 1998).

Secondly, lack of practice training of environmental law. It is necessary for students to improve their practical abilities of law in the environmental law education. If they know the specifications and its relationship of Prevention and Control of Environmental Pollution Law, Protection of Natural Resources Law, International Environmental Law, the college students can improve their ability to implead and cope with the disputes of environment and resources according to the specification of Natural Resources and Environmental Protection Law. They can also improve their ability to apply it correctly by deeply understanding the relationship and differences among Natural Resources and Environmental Protection Law, the related substantive and procedural laws. All of these is absent from our present legal education (Dong \& Wang, 2006). It is common for our students who major in law have poor ability to practice. And other students' practice shine light in this respect. It generally reflects that the law graduates are lack of ability to practice and they do not understand the way of law's practical operation. They apply the laws simply and mechanically. They can not respond to the emergencies, the difficult and complex case owing to lack of comprehensive analysis for a specific circumstance of the case. According to the experience of judicial departments, they will be able to hear the cases, handle the cases and act as agent of various legal affairs at least three or four years later when they graduated from colleges and universities to work in the legal practice department (Zhou, 2006). Therefore, the environmental law education should be provided the necessary legal vocational training for students.

\section{Solutions}

We must combine environmental education about basic knowledge with legal vocational training of environment. Like most countries in the world, legal education is a kind of undergraduate education in China and students have no background for other higher education before entering law school. But the legal education is a kind of graduate education in the United States where students are asked to be must receive the related disciplines for 4 years before enrollment. Because the legal system is a standard rules for all aspects of the state and social life, the effective learning to laws needs a wide range of basic academic knowledge as support. Thus, environmental law education should also reinforce the related basis theoretical knowledge of environment.

Firstly, talking about the basis theoretical education of environment. All universities should offer a specialized compulsory course of environment education about environmental legal education. This course should include all aspects of environmental knowledge, like environmental law education, environmental ethics education, environmental protection. The undergraduate students will be educated the specialized environmental laws education in turn.All schools should also offer the course of environmental law education in relation to professional course for the feature of discipline. University is a cradle to cultivate the specialized qualified talents and different disciplines have different features, so they have different effects on environment. Accordingly, all schools should offer this course which are highly targeted for their students according to their own professional features in order to improve their sensitivity to the environmental influence, in addition, to help them to comply with the regulations of environmental law and improve their environmental consciousness in the future of their design or work. Colleges and universities should also offer the elective courses in relation to environmental laws to meet different students' demand for the knowledge of environmental law. This educational plan is to make up for a lack of the both above, to meet the needs of different students from different majors and to cultivate the compound talents for the modernization construction of our country, the school should offer some elective courses to meet the students' need for different knowledges.

Secondly, talking about legal vocational training of environment. It can be divided into two modes of different trainingtraining in the classroom and outside of classroom.

Legal vocational training of environment in the classroom. Environmental laws can not be separated from the practice and it. It is an important part of the environmental law education. The case teaching method in it is especially for first. This teaching method in the legal education has always been emphasized, and its importance goes without saying (Dou, 2009). Like Ron Dyer said: "Law as a science consists of certain principles or doctrines. To have such a mastery of these as to be able to apply them with constant facility and certainty to the ever-tangled skein of human affairs, is what constitutes a true lawyer ... and the most effective method to grasp these principles is learning cases including these principles."

It can be divided into two kinds for the teaching cases of this course. One is the type of description, the other is the type of discussion. The former is used to illustrate these rules or principles to help students to understand and deepen their impression for the case after it is introduced a rule or principle of a law. These cases are usually simple and less controversial and are mostly used at ordinary times. Of course, this teaching method is also very important, but it is more as a supplementary means to learn its theory. The latter is a more complex and controversial cases and can be argued from different points. It is often the headspring of some new rules and legal thoughts and also the best resources to train students' abilities of environmental law thinking.

Legal vocational training of environment out of the classroom. It can help students to obtain more perceptual understanding and arouse students' enthusiasm for learning. This 
display uses Q and A of environmental law to fully mobilize their initiative in active learning. This teaching method is trying to make the courses meaningful and interesting for them to learn and relax, and it will be to enhance students' learning motivation and make students participating the activity consciously. Not only it is a kind of improvement for participants, but also it can be obtained some environmental legal knowledges in the process for the audiences. Furthermore, they are organized to take part in the practice of environmental protection. Facts speak louder than words, colleges and universities should organize students to participate in various practices of environmental protection to realize the importance of environmental protection for themselves, legal knowledge in environment for environmental protection and protecting themselves environmental rights by means of law in the process. It can fundamentally inspire the students' desire to learn the knowledges of environmental law by this means. Firstly, they are encouraged to establish association in relation to environmental education and environmental laws (Peng, 2011). Association activities is a highlight on campus, student fraternities and societies to create by themselves can undoubtedly play a good role in promoting environmental legal education for them. Encouraged by the relevant associations, they can apply the knowledge of environmental law in the classroom to practice and learn more knowledges from practice, it is truly to do that it comes from practice to practice.Secondly, it is also an important platform for association to promote the knowledge of environmental law. They will hold various activate through their independent operation and promote each other. It can often bring many students to join in this group and this knowledge can be continuous effectively spread among them. Thus, the simulation activities should be established like moot court, case stimulation and so on. Such activities not only can enrich their environmental legal knowledge, but also make them realize legal seriousness and inviolability. They will also be realized the damage to the society and the human cased by environmental law violations. This is a preparation for them to later formally participate in the judicial activities through their simulating experience. Ultimately, it can help them to improve their environmental crisis awareness and remind them to solve it by means when they encountered the environmental problems. It can really be transferred into their power of external behavior.

\section{Conclusion}

In the eighteenth report "Promotion of ecological civilization", comrade Hu Jintao puts forward that, "the construction of ecological civilization is a long-term task for the well-being of people and China's future. Faced with increasing resource constraints, severe environmental pollution and ecosystem degradation, we must foster our ecological civilization's idea to respect for, comply with and protect nature. It should be put in a prominent position and be a part of economic, political, culture and social construction. It helps us to work hard to build our beautiful country ... create a good working and living condition for people and contribute to the ecological security for world (Li, 2001)." It plays a positive, far-reaching role to construct ecological civilization, build our beautiful country, create a good working and living condition for people and contribute to ecological security for world.

\section{REFERENCES}

Dong, X. Z., \& Wang, Y. M. (2006). The importance of environmental education in the environmental course. Journal of Tangshan College, 3, 102-105.

Dou, X. D. (2009). Research on the operation system of environmental law clinic. Legal System and Society, 2, 110-113

Li, S. H. (2001). Strengthening the ecological moral education for college. Leading Journal of Ideological \& Theoretical Education, 11, 33-36

Peng, L. W. (2011). Ecological personality on the right. Law Science Magazine, 7.

$\mathrm{Xu}, \mathrm{H}$. and Zhu H. X. (1998). Theory and practice of international environmental education. Beijing: People's Education Press.

Zhou, Z. R. (2006). Seeing legal education from the quality defects of law graduates. Legal Daily. http://www.sina.com.cn 